\title{
Design, Specification and Tolerancing of Micrometer-Tolerance Assemblies
}

Dennis A. Swyt

U.S. DEPARTMENT OF COMMERCE Technclogy Administration National Institute of Standards and Technology

Precision Engineering Division

Gaithersburg, MD 20899

QC

100

NLT

.056

N0. 5615

1995 



\section{Design, Specification and Tolerancing of Micrometer-Tolerance Assemblies}

Dennis A. Swyt

U.S. DEPARTMENT OF COMMERCE Technology Administration

National Institute of Standards

and Technology

Precision Engineering Division

Gaithersburg, MD 20899

March 1995

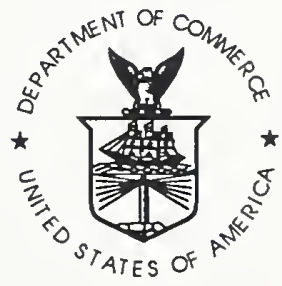

U.S. DEPARTMENT OF COMMERCE Ronald H. Brown, Secretary

TECHNOLOGY ADMINISTRATION

Mary L. Good, Under Secretary for Technology

NATIONAL INSTITUTE OF STANDARDS

AND TECHNOLOGY

Arati Prabhakar, Director 



\section{ACKNOWLEDGEMENTS}

This is to thank those in industry who have provided me ideas and information, including Bill Brockett, Al Nelson, Al Sabroff, Jim Salsbury, and Barry Woods and those at NIST who provided ideas and helped me shape the material, especially Clayton Teague, Ted Hopp, Kari Harper, and Janet Land. 



\title{
Design, Specification, and Tolerancing of Micrometer-Tolerance Assemblies
}

\author{
Dennis A. Swyt \\ National Institute of Standards and Technology
}

\section{Introduction}

Increasing numbers of economically important products manufactured by U.S. companies are comprised of assemblies of component parts which have macroscopic dimensions and microscopic tolerances. The dimensions of these parts range from a few millimeters to a few hundred millimeters in size. The tolerances on those dimensions are of the order of micrometers. Such micrometer-tolerance assemblies include not only electronic products and hybrid electronic-mechanical products, but purely mechanical devices as well. Thus, micrometertolerance assemblies include not only integrated-circuit devices and magnetic-memory read-write heads, but automobile-engine systems, including fuel injectors, hydraulic valve lifters and even piston and cylinder assemblies. Focusing on these, this paper: 1) reports examples of micrometer-tolerance assemblies; 2) discusses strategies in design, specification, and tolerancing (DS\&T) which some companies have adopted for the manufacture of such assemblies; and 3) identifies generic-technology, measurement, and standards issues in DS\&T associated with that manufacture.

\section{Scope, Challenge, and View of Micrometer-Tolerance Assemblies}

This first section of the paper defines the scope of micrometer-tolerances assemblies in terms of examples of currently manufactured products, suggests the challenge to manufacturing which these assemblies represent, and introduces a product cycle view of DS\&T as the basis for further discussion .

\section{1a. Dimensions and Tolerances of Representative Micrometer-Tolerance Assemblies}

Figure 1 shows tolerances and dimensions for components of products comprised of micrometer-tolerance assemblies. In decreasing order of size, the examples in Figure 1 include: hydraulic systems of heavy equipment with $300 \mathrm{~mm}$-long cylindrical elements having geometric tolerances of $\pm 1 \mu \mathrm{m}$ to $\pm 3 \mu \mathrm{m}$; mid-precision automobile engine pistors tolerance to $7.5 \mu \mathrm{m}$ to $10 \mu \mathrm{m}$; the highest-precision pistons toleranced at, or possibly below, $1 \mu \mathrm{m}$; and fuel-injector plunger-bore assemblies with form tolerances of less than $\pm 1 \mu \mathrm{m}$ and size-class tolerances of $\pm 0.5 \mu \mathrm{m}$. Also in this range of interest are suspensions of magnetic-memory read-write heads with parts millimeters in size with sub-micrometer tolerances. For comparison, some precision-tolerance assemblies of very large- and small-scales are also shown. These include: $35 \mathrm{~m}$ wing spars of a commercial jet liner with design-goal tolerances on fastener hole locations of $\pm 750 \mu \mathrm{m}$; luxury-class automobile bodies with $5 \mathrm{~m}$ body-inwhite assembly tolerances of $\pm 250 \mu \mathrm{m}$; naval marine propulsion gears 600 -mm wide with axes-parallelism tolerances of $2 \mu \mathrm{m}$; and telecommunication optical fibers of $125 \mu \mathrm{m}$ diameter with $0.2-\mu \mathrm{m}$ tolerances. For further comparison also shown are the 0.35 - $\mu \mathrm{m}$ dimensions and $0.035 \mu \mathrm{m}$ tolerances of production state-of-the-art microelectronic devices. 


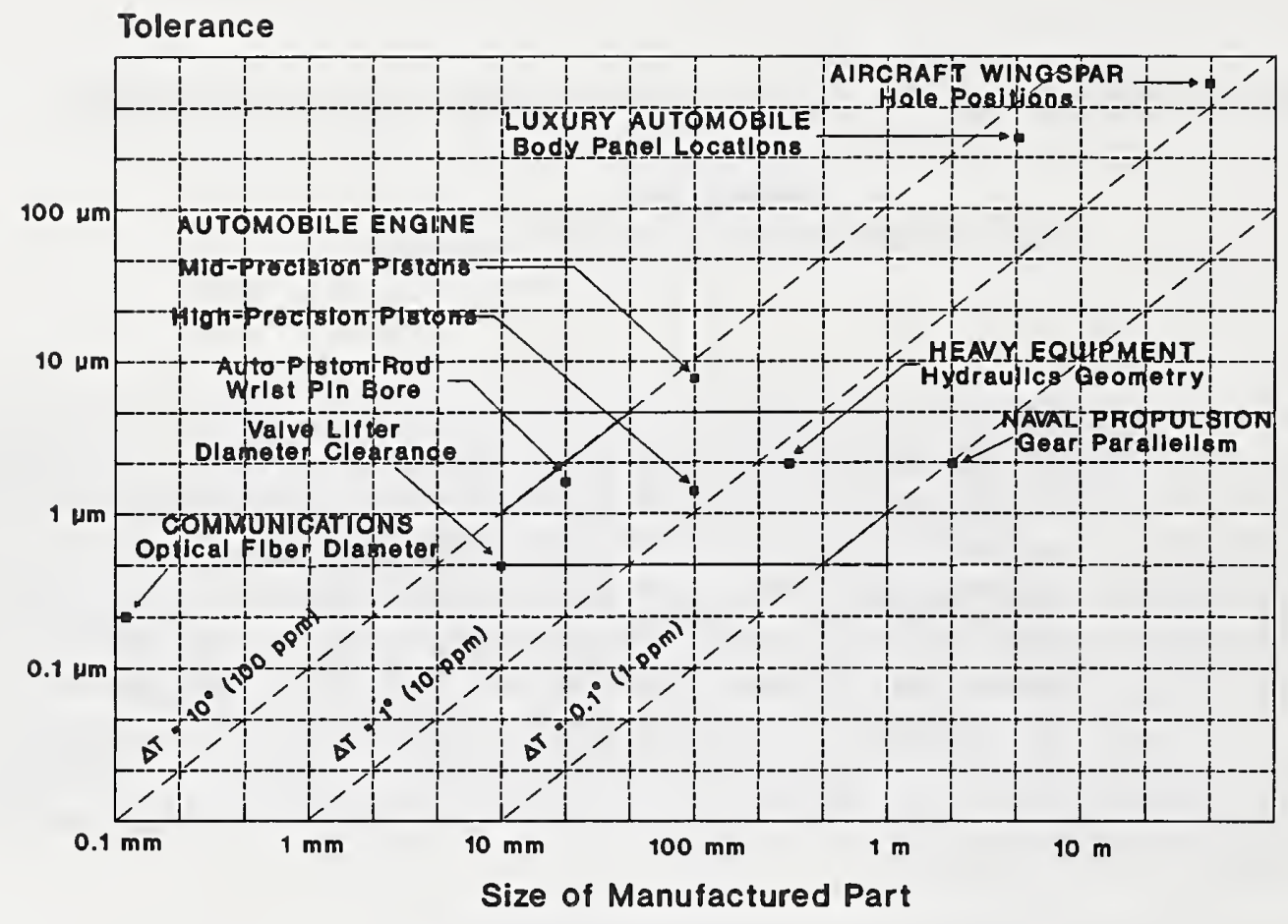

Figure 1 Tolerances and dimensions for components of some micrometer-tolerance assemblies

\section{1b. The Challenge of DS\&T of Micrometer-Tolerance Assemblies}

One of the challenges in manufacture of micrometer-tolerance assemblies is control of dimensions given changes in temperature of the production environment. To suggest the magnitude of this problem, Figure 1 shows the intersection of three isotherms, two dimensions, and two tolerances. The two dimensionsare $10 \mathrm{~mm}$ and $1000 \mathrm{~mm}$. The two tolerances are $0.1 \mu \mathrm{m}$ and $10 \mu \mathrm{m}$. The three isotherms represent changes in length of 1 $\mathrm{ppm}, 10 \mathrm{ppm}$, and $100 \mathrm{ppm}$ (parts per million) corresponding to changes in temperature of $0.1^{\circ} \mathrm{C}, 1^{\circ} \mathrm{C}$ and $10^{\circ} \mathrm{C}$ for a material, such as steel, with a coefficient of thermal expansion of $10 \mathrm{ppm} /{ }^{\circ} \mathrm{C}$. The implication for the degree of temperature control required for manufacture of macroscopic-size parts to $1 \mu \mathrm{m}$-level tolerances is apparent. For example, for the thermal variation in size of a $100 \mathrm{~mm}$ steel part to represent less than $10 \%$ of a $1 \mu \mathrm{m}$ part tolerance, a temperature control of better than $0.1^{\circ} \mathrm{C}$ is required.

Another of the challenges in manufacture of micrometer-tolerance assemblies is suggested by Figure 2. This challenge is the achievement of tolerances which represents limiting values of standardized tolerance grades, the most finely formed manufactured parts, and the most advanced manufacturing processes. Shown in Figure 2 are component dimensions and tolerances and the International Tolerance Grades, representative manufactured parts, and typical manufacturing processes to which they correspond. Drawn for this paper, Figure 2 is based on tabulated tolerances and dimensions. Not all have been drawn. Here, as in the tabulated data, not every size- 


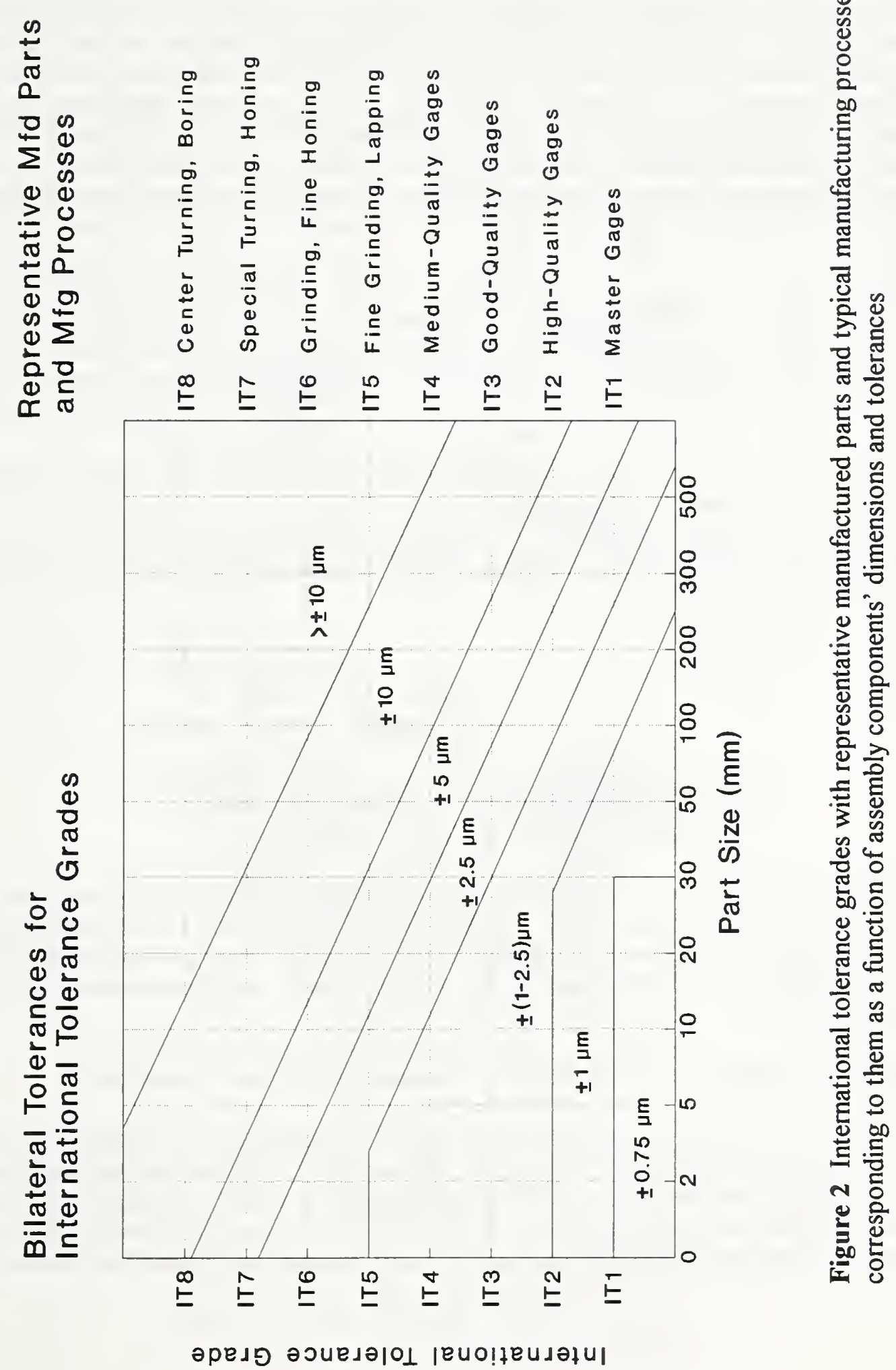


tolerance combination corresponds to one tolerance grade. For the values upon which Figure 2 is based, see the customary-unit standard [1], its metric equivalent [2], or an appropriate engineering reference $[3,4]$.

To determine a tolerance grade for a toleranced part from Figure 2, locate the size of the part in millimeters on the horizontal axis, move up to the line which represents the nearest value to the part tolerance in micrometers, move horizontally to the left to read the tolerance grade, and move horizontally to the right to read the products and processes representative of the difficulty of manufacture of that size-tolerance combination. For example, for a $100 \mathrm{~mm}$ part size with a tolerance of $\pm 10 \mu \mathrm{m}$, the tolerance grade would be IT6, represented by grinding and fine honing. As indicated by Figure 2, components with dimensions and tolerances respectively of $300 \mathrm{~mm}$ and $2.5 \mu \mathrm{m}, 100 \mathrm{~mm}$ and $1.5 \mu \mathrm{m}$, and $10 \mathrm{~mm}$ and $0.5 \mu \mathrm{m}$ each belong to International Tolerance Grade 1 .

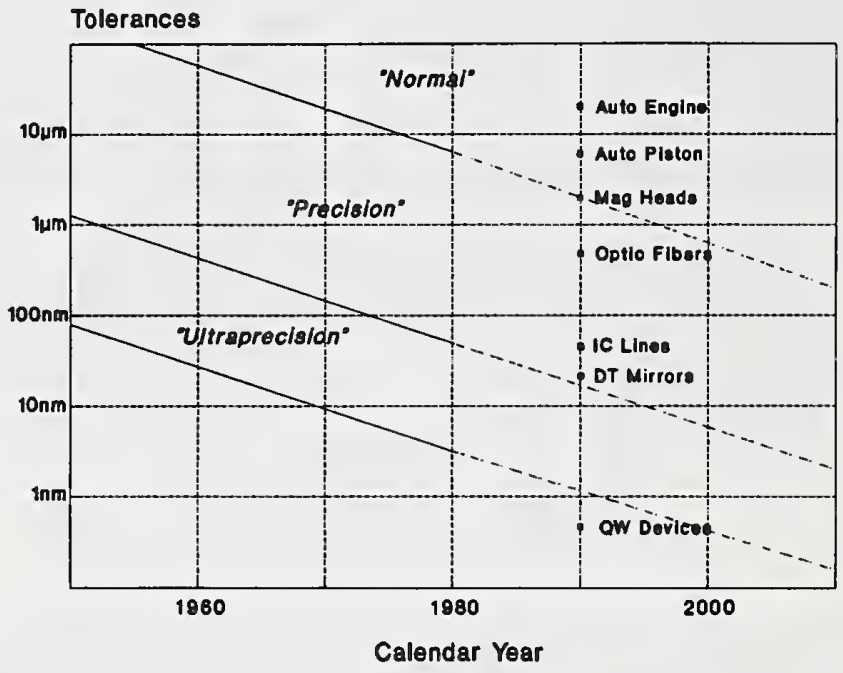

Figure 3 Trend in part tolerances showing tightening at average rate of a factor of ten every twenty years

Figure 3 shows why many of today's mass-produced goods have components with tolerances corresponding to those of carefully crafted master gages of the near past. This remarkable fact can be understood in terms of the trend in tolerances on manufactured goods shown by the figure. According to this trend, tolerances on manufactured products have been decreasing in magnitude at an average rate of approximately a factor of ten every twenty years $[5,6]$.

\section{1c. A Product-Cycle View of Issues in DS\&T of Micrometer-Tolerance Assemblies}

One of the most effective means for manufacturers to deal with the challenges of ever-tightening tolerances is to take into explicit account the whole product cycle when designing, specifying, and tolerancing assembled products. Here design, specification, and tolerancing is considered to consist of the three interrelated tasks: design, meaning to plan the form and structure of the assembly and its components; specification, meaning to provide a detailed description of requirements, materials, and dimensions; and tolerancing, meaning to set the 


\begin{tabular}{|c|c|c|c|}
\hline Design & Component & Assembly & Product \\
$\begin{array}{c}\text { Design, } \\
\text { Specification } \\
\text { Tolerancing }\end{array}$ & $\begin{array}{c}\text { Fabrication } \\
\text { and } \\
\text { Measurement }\end{array}$ & $\begin{array}{c}\text { Assembly } \\
\text { and } \\
\text { Testing }\end{array}$ & $\begin{array}{c}\text { Customer } \\
\text { Evaluation } \\
\text { and Use }\end{array}$ \\
\hline
\end{tabular}

Table 1. Design, specification, and tolerancing within the phases of product cycle of an assembled product

permissible range of variation in those dimensions. Table 1 shows schematically the major functional elements of a simplified product cycle for an assembled product. In terms of a logical progression of functional stages, these main elements are: 1) the Design stage, which includes design, specification, and tolerancing of both the product and physical processes used in its production; 2) the Component stage, which includes component part fabrication and metrology; 3) the Assembly stage, which includes assembly operations and performance testing; and 4) the Product or customer stage, which involves the customer's ultimate use and evaluation of the product. The following section discusses issues in the design, specification, and tolerancing of micrometer-tolerance assemblies in terms of this product cycle.

\section{Strategies for DS\&T of Micrometer Tolerance Assemblies}

This part of the paper looks at the manufacture of a number of micrometer-tolerance assemblies found in the modern multi-valve, fuel-injected automobile engine. The challenges associated with the manufacture of these

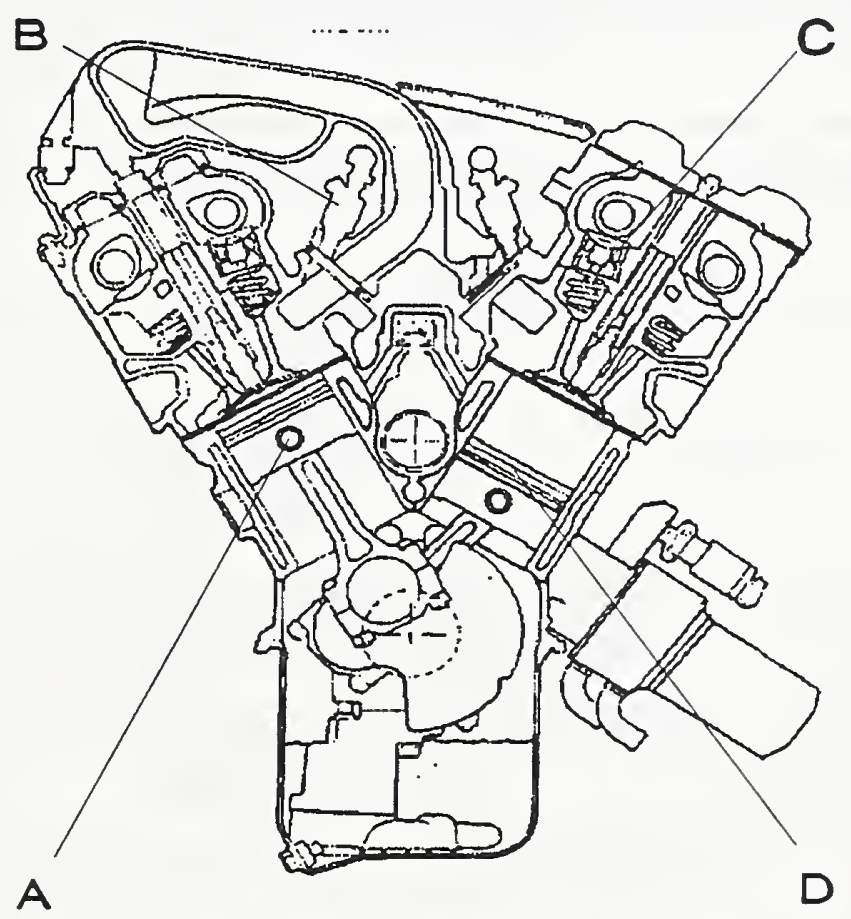

Figure 4 Cutaway of fuel-injected twenty-four-valve twin dual overhead cam v6 engine: A) piston-rod-wristpin assembly; B) hydraulic valve lifter assembly; C) fuel injector assembly; and D) piston-ring-cylinder assembly. 
assemblies represent those encountered by industry in the manufacture of many other types of products comprised of micrometer-tolerance assemblies. As indicated by Figure 2, one aspect of that challenge is to mass produce these assemblies to tolerance grades corresponding to those of high-quality (IT2) and master (IT1) gages.

Figure 4 is a cutaway drawing of a modern automobile engine. This particular one is a fuel-injected twenty-fourvalve twin dual overhead cam V6. In this engine are four assemblies which have components some of which are now toleranced to tolerance grades IT2-IT1. These are: A - the piston, rod, and wrist pin assembly; B - the valve lash-adjuster assembly; $\mathrm{C}$ - the fuel-injector plunger and bore assembly; and D - the piston and cylinder assembly.

Each of these engine-system assemblies shown in Figure 4 has components $10 \mathrm{~mm}$ to $100 \mathrm{~mm}$ in size which, in special cases to be discussed, are toleranced in the range of $0.5 \mu \mathrm{m}$ to $1.5 \mu \mathrm{m}$. Each of them is comprised of a cylindrical-fit assembly. Of the three types of assembly fits, length, multi-fastener and cylindrical, the latter is the most difficult to design, specify, tolerance and manufacture. Yet, each of the four examples in the engine shown in Figure 5 must be produced in high volume at low cost. As a result, the DS\&T of these assemblies calls for special strategies. A major choice in strategy is whether to use single- or multiple-size-class assembly. In the interchangeability or single-size-class strategy, control over fabrication processes is such that the manufacturing deviations of both part and counterpart fall within limits which allow complete interchangeability. In this case, any part fabricated may be assembled with any counterpart fabricated to produce an assembly, which has assembly deviations that fall within permissible limits. This is to say, components individually within tolerances will yield assemblies within tolerances. Where manufacturing deviations among components will not allow interchangeable assembly, there are two principal alternatives. The extreme alternative is individual

\begin{tabular}{|c|c|c|c|}
\hline Category & Limits & Mean & Tolerance \\
\hline & 20.644 & & \\
\hline \multirow[t]{2}{*}{1 Yellow } & & 20.6425 & $\pm 1.5 \mu \mathrm{m}$ \\
\hline & 20.641 & & \\
\hline \multirow[t]{2}{*}{2 Blue } & & 20.6395 & $\pm 1.5 \mu \mathrm{m}$ \\
\hline & 20.638 & & \\
\hline \multirow[t]{2}{*}{3 Red } & & 20.6375 & $\pm 1.5 \mu \mathrm{m}$ \\
\hline & 20.635 & & \\
\hline \multirow[t]{2}{*}{4 White } & 8 & 20.6335 & $\pm 1.5 \mu \mathrm{m}$ \\
\hline & 20.632 & & \\
\hline
\end{tabular}

Table 2 Size-class categories for wrist pin of $1.5 \mu \mathrm{m}$-tolerance piston-rod-wristpin assembly 
match-fit assembly. This is the approach in which a part is fabricated to a dimension determined by the measured dimension of a previously fabricated and measured counterpart.

Between the extremes of interchangeable assembly and individual-match-fit assembly is the strategy of sizeclass assembly. In size-class assembly, either or both part and counterpart are measured after fabrication. They are then sorted into size categories, that is, size classes.

Table 2 shows dimensions and tolerances for such a size-class system. The number of classes, $\mathrm{n}$, depends on how much the range of manufacturing deviations of the fabricated parts must be divided to achieve an acceptable level of assembly variation. The size-class tolerance is equal to the component fabrication-process tolerance divided by $n$. Interchangeability is, in effect, $n$-equal-one or single-size-class assembly. The number of size classes is chosen to give a size-class tolerance which will yield the required assembly tolerance. The next sections discuss each of the four micrometer-tolerance assemblies shown in Figure 4 in terms of the DS\&T strategies, which their manufacturers are pursuing. The foremost questions are when and why to use either multiple- or single-size-class assembly.

\section{2a. Piston-Rod-Wristpin Assemblies}

Figure 4-A shows the engine's piston, rod, and wrist pin assembly. Piston, rod, and wrist-pins are also micrometer-tolerance assemblies produced by a DS\&T strategy of size-selective assembly. In the case of the manufacture of the 1.9-liter engine of a U.S.-made automobile which enjoys large sales in the global car market, implementation of the size-class DS\&T strategy involves selecting made-to-size-class pins to fit measured bores. As shown in Table 2, the nominal diameter of the bored hole in the piston rod is approximately $20 \mathrm{~mm}$ with a tolerance range of $12 \mu \mathrm{m}$. For the assembly process, $100 \%$ of pin bores are gaged for size and sorted into four size-classification grades with half-width tolerances of $\pm 1.5 \mu \mathrm{m}$. Mating pins are machined to size to the mid-ranges of the four size categories and to tolerances of $\pm 1 \mu \mathrm{m}$. Size-classed pins are machine selected for assembly with known-size bores. In terms of a trend in capabilities, the current four-category size classification is down from seven two years ago. Planned acquistion of a new hole-boring technology is intended to move the plant multiple-size-class to single-size-class assembly within two years.

\section{2b. Valve-System Assemblies}

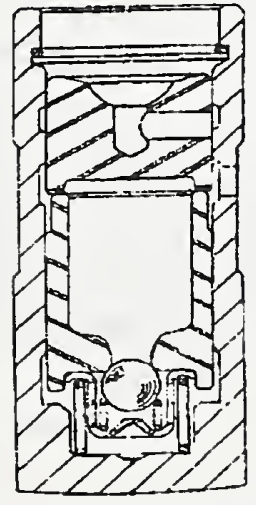

Figure 5 Cutaway view of a hydraulic valve lifter (or llash adjuster) assembly.
Figure 4-B shows for the example engine the location of one of the hydraulic valve lifters (or lash adjusters).

Figure 5 shows a detailled cutaway view of the device. A valve lifter (or lash adjuster) is a mechanism that compensates for thermal expansion and wear in the maintenance of the clearance between valve-gear components when the valve is seated. It is essentially a closed hydraulic cushion that operates with a leak-down rate precisely controlled by the clearance between the body and the plunger and the opening between the valve and the seat.

To serve production of over 15 million automobile engines (with up to 32 valves each), per year, as well as the aftermarket, three U.S. manufacturers together produce valve lifters (or lash adjusters) at the rate of approximately 200,000 per day or 500 million per year. With introduction of down-sized and multi-valved engines, new smaller-valve assemblies need to be produced with tolerances on cylindical fits and valve-seat 
openings in the range of $1-5 \mu \mathrm{m}$. The DS\&T strategy is that for a production process in which components are individually gaged, sorted into size classes, automatically selected by size and automatically assembled with measured counterparts, and $100 \%$ proof tested for functionality.

\section{2c. Fuel-Injector Assemblies}

Figure 4-C shows the engine's fuel-injector assembly. Fuel-injector plunger-bore assemblies have some of the tightest tolerances on size of any mechanical component in an automobile engine. Micrometer-level geometrical and dimensional tolerances on fuel injectors derive from the fuel-metering pupose of the assembly and the slidingseal relation of its moving parts. Until relatively recently, the geometric and dimensional tolerances of "fit, form, and finish" on fuel-injector type assemblies followed the rule of thumb: form tolerances which are 1/8 those of size and surface-finish values which are $1 / 8$ of tolerances on form. For example, by this rule a part would have a size tolerance of $10 \mu \mathrm{m}$, a form tolerance of $1.25 \mu \mathrm{m}$, and a surface finish of $0.15 \mu \mathrm{m}$. In contrast, a $10 \mathrm{~mm}$ size fuel injector today might have form error under $1 \mu \mathrm{m}$, a size-class tolerance of $0.5 \mu \mathrm{m}$, and a surface finish of the order of $0.025 \mu \mathrm{m}$. The overall strategy for mass producing these especially tight-tolerance cylindrical-fit assemblies is to grind the plungers, hone the bores, air-gage them for size, sort them to size classes, and use size-selective assembly.

\section{2d. Piston-Cylinders Assemblies}

To achieve the desired functionality in valve-adjusters, fuel-injectors, and piston-rod assemblies just discussed, in a number of cases their components are now or about to be toleranced more closely that can be economically achieved with truly interchangeable parts. As a result, the dominant strategy for DS\&T of the components of these assemblies has been what is variously called the size-and-sort, size-selective, or size-classification method of assembly.

Figure 4-D shows the engine's piston-cylinder assembly. Historically produced by the DS\&T strategy of sizeselective assembly, combustion-engine pistons and cylinders are now being produced by certain companies in single-class sizes. The evolution of these companies from multiple- to single-class size-selective assembly represents a trend in the thinking and practices of the auto industry as a whole.

\section{Product-Cycle Considerations in the DS\&T of Micrometer-Tolerance Piston-Cylinder Assemblies}

As in the previous auto-engine examples,piston-rings-cylinder assembly involves mass production of highquality assemblies which have components with tolerances in the range $0.5 \mu \mathrm{m}$ to $10 \mu \mathrm{m}$ and which involve cylindrical-fit assembly, the most difficult type. As in the case of the piston-rod-wristpin assemblies, the overall industry practice is at the transition from multiple- to single-class size-selective assembly. Within an individual company, the choice of DS\&T strategy of multiple- or of single-size classes involves considerations of each of the functional design, component fabrication, assembly, and customer-use stages of the product cycle.

\section{3a. DS\&T and Engine Performance}

In the case of the piston-cylinder assembly, a number of engine-performance attributes require close and carefully controlled clearance fits in the assembled engine. Characteristics of engine performance which depend on pistonring-cylinder fit include engine noise, fuel economy, engine wear, and pollutant emissions. Tolerancing to control piston and cylinder size and geometry to achieve specific engine performance characteristics involves trade-offs in a complex of cost-benefit, gain-loss relations, including those for tighter-versus-looser fits of 
piston and cylinder bore. One design consideration which calls for a tighter fit is reduced cold piston slap. One which calls for looser fit is less skuffing of piston skirts against cylinder walls. Even in this simple case, factors other than the relative size of pistons and cylinders enter into tolerancing to control piston-cylinder clearance, including piston skirt shape, flexibility, and projected area.

\section{3b. DS\&T and Component Fabrication}

U.S. car companies are just now beginning to achieve the ability to fabricate piston-cylinder assemblies with micrometer-level tolerances. Because, in general, an outside diameter can be more readily machined to a given tolerance than an inside diameter can be, pistons and pins can be turned with smaller deviations from a target dimension than engine blocks and other holes can be bored. Piston diameters can carry tolerances tighter than those of cylinder bores.

Up to two decades ago, grinding was the dominant manufacturing process for fabricating pistons to final dimension. Beginning then, industry switched to single-point precision machining, a process which continues to be the norm today. The range of tolerances on piston diameters is generally $12 \mu \mathrm{m}$ or more for the widertolerance pistons, $7.5 \mu \mathrm{m}$ accuracies to $10 \mu \mathrm{m}$ for the mid-range, and less than $7.5 \mu \mathrm{m}$ for the more precise. Without specifying the attainable, developers of a technique for software-based temperature error correction of piston turning machines have reported a five-fold improvement in the accuracy with which pistons can be singlepoint turned in shop-type thermal environments. Assuming that that five-fold improvement is relative to the range $7.5 \mu \mathrm{m}$ to $12.5 \mu \mathrm{m}$ of the pistons reported in this paper, such a software-corrected piston-turning machine would be able to machine pistons to size tolerances somewhere in the range of $1.5 \mu \mathrm{m}$ to $2.5 \mu \mathrm{m}$.

Another innovation in cylinder-bore manufacturing is reaming with a diamond tool followed by two-pass honing. The primary purpose of the diamond reaming is to improve bore cylindricity and control stock removal required during the honing process which produces the final size and bore finish. Both the diamond reaming and the twopass honing operations employ automatic gaging of part size. The doamond reaming process is compensated based on a moving average of the measured size. The final honing process is to size for each bore.

As these developments in piston and bore fabrication capability suggest, a major consideration for component fabrication is which of the overall DS\&T strategies is to be pursued: true interchangeability; selective assembly; or part-counterpart fitting. By industry accounts, the price, volume, and required quality of components being fabricated determine the choice. For example, a U.S. company which is a builder of heavy off-road trucks and a major supplier of engine components to automobile manufacturers uses both size classification and part-counterpart fitting, depending on the functional requirements and price-volume economics of the assembly. For production of power steering units of expensive built-to-order off-road trucks, hydraulic pistons are fabricated to micrometer tolerances on size by match-grinding to the dimension of specific cylinders. For the 100,000 per day production of auto-engine valve assemblies, hydraulic pistons are fabricated to micrometer-level tolerances on clearance fits by size- sorting. Note that one of the primary considerations for moving away from multiple- to single-size is the elimination of "mis-builds", that is, out of tolerance assemblies due to the gaging error which causes overlapping of classes. With single-class sizing, the end result is less variation over the population. To implement single-class sizing, statistical process control in component fabrication is a necessity.

\section{3c. DS\&T and Assembly Operations}

While perceived by some as being universal practice for piston-cylinder assembly by all the world's auto makers, 
size classification has been giving way to true interchangeability. This is partly because of increased capabilities to manufacture pistons and cylinders to increasingly tighter tolerances. As a result, the auto industry is advancing toward single-size assembly operations. This movement by industry as a whole is indicated by the progressive decrease in the number of size classifications individual car makers employ. For example, at an engine plant of one U.S. car company, the number of piston-bore size classifications has progressively decreased from thirteen categories twenty years ago, to nine categories fifteen years ago, to four categories ten years ago, to single-size classification today. Apparently two of the four indigenous U.S. car companies have achieved the capability of single-size-class assembly of pistons and cylinder bores, doing so since 1988.

\section{3d. Optimization over the Product Cycle}

Manufacture of automobile-engine piston-cylinder assemblies exemplifies how system-level views lead to rational bases for deciding among alternative strategies in design, specification, and tolerancing.

Single-vs-Multiple Size Classes, Tight-vs-Loose Tolerances One simple subset of alternative approaches includes deciding multiple- versus single-class sizing and tighter versus looser tolerances. While single-class tight-tolerance components seems to be the evolutionary ends toward which U.S. automobile manufacturers are tending, number of size classes and the tightness of tolerances are separate choices. For example, speaking about the achievement of single-size manufacture, the quality systems manager at a company that uses tight-tolerance single-class sizing of pistons and cylinders points out that tight tolerancing per se is not the only route to singleclass sizing. Another route is knowing what the total system requires and then putting the allowable variations where they can be controlled. In effect, a similar result can be achieved by either relaxing tolerances on pistons to that which can be achieved on bores or tightening tolerances on bores to that which can be achieved on pistons. In either case, one U.S. car company known to be using single-class sizing of pistons and cylinders "backs away" from micrometer-level tolerances. Instead it pursues a strategy of treating them as something to be designed out, not in. In both of these cases, choice of specific tolerances by the car companies using single-size assembly is the result of front-end design considerations that took into account the later stages of the engine's product life cycle. These considerations were of the functional dependence of tighter or looser tolerances on the quality (performance, reliability, cost, and availability) of the assembled system, on the assembleability of components, and on the manufactureability of the components themselves in a modern versions of engineering tradeoffs.

Quality-Loss Approach to Choosing Tolerances The logic of the quality-loss-function approach advocated and employed by the quality system manager of the engine plant using single-size piston-cylinder assemblies and microsizing of piston bores for dealing with performance-cost tradeoffs in design, specification, and tolerancing of engine components involves a number of considerations. The first consideration is that manufacturing costs, in general , have an inverse relationship with both clearances and tolerances. Costs increase as clearances and tolerances decrease. The second consideration is that some attributes of engine performance improve when clearances are decreased, some when they are increased. The third consideration is that a complete mathematically-represented cost-benefit versus tolerance relationship is virtually unattainable. Given these considerations, the automobile manufacturer using tight-tolerance single-class sizing applies Taguchi's designof-experiments approach. The objective is to dimension and tolerance the assembly to lie at the looser-tolerance end of a "flat" region of the customer-perceived quality loss function.

Variation Simulation and Choices A tool which supports the experiment-design approach to DS\&T and allows search for flat spots in quality loss function is "variation simulation analysis. This is a software tool for quantitative analysis of the effects of dimensions and tolerances on ease of assembly and functionality. The approach combines 3D solid modeling of dimensioned and toleranced parts with Monte Carlo statistical 
modeling of assembly operations. The software simulation predicts the amount of variation that will occur in an assembly due to component variation, assembly methods and assembly sequences. This simulation is used by a number of builders of cars and trucks, as well as their suppliers. Some of them report anaability not only to avoid overly tight tolerances, but to reduce current ones as well $[7,8]$.

\section{Dimensioning and Tolerancing Micrometer-Tolerance Cylindrical-Fit Assemblies}

The previous section discussed the DS\&T of micrometer-tolerance automobile engine assemblies from the perspective of the overall product cycle. The following section looks at those same assemblies from the perspective of geometrical dimensioning and tolerancing of components for function as parts of those assemblies.

\section{4a. Representative Cylindrical-Fit Assemblies}

Table 3 shows dimensions and tolerances for the pistons and cylinders of a U.S. car company's 3.4-liter multivalve twin dual cam engine. The dimensions include the diameters of the piston and of the cylinder and their difference, that is, the clearance between them. The tolerances include those on the size of the piston and cylinder, on their clearance, and on their roundness. In this case, the size and form tolerances are respectively the same for piston and cylinder. They are approximately equal to each other and are approximately one-fifth of the size of the clearance.

Table 4 shows size and form tolerances for cylinder bores of three U.S.-made automobiles with multi-valve engines, the first with size-selected pistons and the other two with single-size. In addition to size tolerances on the piston and cylinder, the table includes two types of form tolerance used on cylinders. First there is roundness. This is a tolerance zone bounded by two concentric circles and which is a measure of the deviations from circularity of a cross-section of a part. Three two-dimensional properties - circularity, straightness, and taper

- taken togeteher have historically been used to control three-dimensional cylindrical form. The table also includes cylindricity, a tolerance zone bounded by two concentric cylinders. Cylindricity is a composite control of form which simultaneously includes circularity, straightness, and taper.

\begin{tabular}{|c|c|c|c|}
\hline $\begin{array}{c}\text { Mating } \\
\text { Parts }\end{array}$ & $\begin{array}{c}\text { Diameter } \\
D\end{array}$ & $\begin{array}{c}\text { Size } \\
\text { Tolerance }\end{array}$ & $\begin{array}{c}\text { Roundness } \\
\text { Tolerance }\end{array}$ \\
\hline Cylinder & $\begin{array}{c}92.029 \\
\mathrm{~mm}\end{array}$ & $\pm 9 \mu \mathrm{m}$ & $7 \mu \mathrm{m}$ \\
\hline Piston & $\begin{array}{c}91.979 \\
\mathrm{~mm}\end{array}$ & $\pm 9 \mu \mathrm{m}$ & $7 \mu \mathrm{m}$ \\
\hline Gap G & $50 \mu \mathrm{m}$ & $\pm 18 \mu \mathrm{m}$ & \\
\hline Ratio & $\mathrm{G} / \delta \mathrm{S}=5.5$ & $\delta \mathrm{G} / \delta \mathrm{S}=2$ & $\delta \mathrm{R} / \delta \mathrm{S}=0.8$ \\
\hline
\end{tabular}

Table 3. Mean diameter, gap, and tolerances for a multivalve engine of a u.s. automobile

Column 4 of Table 4 shows the specifications for Engine \#3 (column 3) scaled to the tolerance on the diameter of its single-size-class piston. Based on column 4, column 5 shows dimensional specifications for a hypothetical 
Engine $\mathrm{X}$ which has a single-class-size piston toleranced to $1.5 \mu \mathrm{m}$. As a size tolerance, this hypothetical value apparently approximates the leading edge of today's single-point piston-machining capability. While not reportedly achieveable with today's manufacturing technology for high-volume piston and cylinder fabrication and gaging, the hypothetical specifications in Table 4 may approximate the proprietary tolerances for crafted Formula I engines. For example, a Japanese automobile manufacturer, which also produces and races Formula-I cars, reports that while the company achieves bore cylindricity of $12.5 \mu \mathrm{m}$ on cast iron engines and $7.5 \mu \mathrm{m}$ on those of metal-matrix composite and size tolerances of $\pm 10 \mu \mathrm{m}$ in each case, the tolerances on its Formula-I engines are a "factor of ten better". Such tolerances would be in the range of $0.75 \mu \mathrm{m}$ to $1.25 \mu \mathrm{m}$.

For comparison Table 5 shows geometrical dimensions and tolerances for a variety of motor-vehicle cylindricalfit assemblies with mean diameters ranging from $5 \mathrm{~mm}$ to $300 \mathrm{~mm}$. The table includes entries for seven automobile engines. Rows $1-4$ of Table 5 show the the tolerances for the three real and one hypothetical engines of Table 4. Rows 5-7 show tolerances for three foreign-company engines. These tolerances represent those on cast-iron pistons and metal-matrix piston-cylinder assemblies and the factor of ten better representative of their Formula I race-car engines. Also shown in Table 5 are tolerances for older and newer generations of valve lifters (or lash adjusters), for a 300-mm long hydraulic valve stem, and for both diesel and gasoline engine fuel injectors.

\section{Gap-Based Design of Assemblies}

The modern mutlti-valve engine illustrates the result of an effective approach to the difficult problem of how best to dimension and tolerance high-precision assemblies such as those in the modern automobile engine. The approach is to focus on the function of the gap, the boundary region between the mating components of the assembly. Depending on the function of the interaction of the mating components of the assembly, this boundary region can have a width the numerical value of which is designed to be positive, negative, or zero. For a clearance fit, the value of the gap is positive. For an interference fit, the gap is negative. For a transition fit, it is zero.

\begin{tabular}{|c|c|c|c|c|c|}
\hline Specification & $\begin{array}{c}\text { Engine } \\
\# 1\end{array}$ & $\begin{array}{c}\text { Engine } \\
\# 2\end{array}$ & $\begin{array}{c}\text { Engine } \\
\# 3\end{array}$ & $\begin{array}{c}\text { Ratios } \\
\text { of } 3\end{array}$ & $\begin{array}{c}\text { Engine } \\
X\end{array}$ \\
\hline $\begin{array}{c}\text { Clearance Gap } \\
\text { Dimension }\end{array}$ & $50 \mu \mathrm{m}$ & $30.5 \mu \mathrm{m}$ & $25 \mu \mathrm{m}$ & $2.5 \cdot \delta \mathrm{D}$ & $4 \mu \mathrm{m}$ \\
\hline $\begin{array}{c}\text { Clearance } \\
\text { Gap Tolerance }\end{array}$ & $\pm 18 \mu \mathrm{m}$ & $\pm 20 \mu \mathrm{m}$ & $\pm 19 \mu \mathrm{m}$ & $2 \cdot \delta \mathrm{D}$ & $\pm 3 \mu \mathrm{m}$ \\
\hline $\begin{array}{c}\text { Diameter } \\
\text { Tolerance }\end{array}$ & $\pm 9 \mu \mathrm{m}$ & $\begin{array}{c} \pm 12.5 \\
\mu \mathrm{m}\end{array}$ & $\pm 10 \mu \mathrm{m}$ & $1 \cdot \delta \mathrm{D}$ & $\pm 1.5 \mu \mathrm{m}$ \\
\hline Roundness & $7 \mu \mathrm{m}$ & $10 \mu \mathrm{m}$ & $10 \mu \mathrm{m}$ & $1 \cdot \delta \mathrm{D}$ & $1.5 \mu \mathrm{m}$ \\
\hline Cylindricity & $\ldots$ & $18 \mu \mathrm{m}$ & $15 \mu \mathrm{m}$ & $1.5 \cdot \delta \mathrm{D}$ & $2.5 \mu \mathrm{m}$ \\
\hline
\end{tabular}

Table 4. Comparison of various cylindrical-assembly tolerances for engine piston-bores in four multi-valve engines, three real and one hypothetical. 
Gap Function For effective DS\&T of precision assemblies generally and piston-cylinder assemblies specifically, the first step in this gap-function approach is to identify the function of the gap. The function of the gap can be, among others, transmission of torque, rotary or linear motion, establishment of position, maintenance of alignment, or combinations of these and other functions. For example, in the case of the automobile piston-ringcylinder assembly, the functions of the gap is to provide alignment for linear motion and maintenance of a sliding seal.

Gap Dimensioning and Tolerancing The second step in the approach is to define the form and width of the gap which its identified function requires. For an automobile piston-cylinder assembly, the geometries of the cylinder wall, piston rings, piston body, and piston skirt need to be chosen to achieve definition and control of gaps designed to yield different types of fits between the cylinder walls and different parts of the piston: first, a non-contact clearance fit between the cylinder walls and the piston body; second, a sliding-contact clearance fit between the cylinder walls and the piston skirt (which must be prevented from becoming a transition fit due to thermal expansion); and, third, a true zero-gap transition fit between the cylinder walls and the piston rings which need be maintained under the range of operating conditions.

Component Functional Geometry The third step in the approach is to determine the geometry which each mating component is to have to maintain the gap between mating components during operation of the assembly. This determination is made by analyzing the mechanical behavior of those mating surfaces as they meet at that boundary. In the case of automobile pistons and cylinders, the design goal is to maintain a constant, linecontact gap during each each sweep of the piston along the cylinder wall. This leads to considerations of a variety of mechanical properties of the piston which ultimately determine piston geometry. For example, these gap considerations include the compliance of piston rings and skirt, the tribology of bearing surfaces, bore distortion under pressure, and bore and piston distortion resulting from thermal gradients up, down and around each of those components. For example, to compensate for distortion due to thermal gradients, the automobile piston is not cylindrical. The cross section made by a plane perpendicular to its axis is elliptical, while that made by a plane containing the axis is barrel shaped, that is, narrower both above and below the pin-bore axis. A zero-clearance, that is, transition, fit between the non-cylindrical piston and cylindrical bore is achieved by means of the compliant rings.

Component Tolerancing The final step in this approach is to choose tolerances for the component parts which insure the achievement, within acceptable tolerances, of a gap dimension which will achieve the gap function intended. Finally, the effective approach to tolerancing of components of assemblies is to view those tolerances as derived from the dimensioning and tolerancing of the gap as a virtual feature, one whichs exist at the interface of the components after they are assembled. Appendix A shows the relationships among gap and component dimensions. It also shows the relationship of gap tolerances and component tolerances in a worst-case analysis of component tolerance stacking for single-size-class components. In that case, the tolerance on the components of a cylindrical fit assembly need be equal to or less than half the tolerance on the gap, that is, $\delta \mathrm{D} \leq 1 / 2 \Delta \mathrm{G}$. Where manufacturing deviations on components are larger than this value, the multiple-size-class strategy is used. In this case, the number of size classes $n$ is chosen such that size-class tolerance is $\delta D_{n} \leq 1 / 2 \Delta G$, where $\delta D_{n}=$ $\delta \mathrm{D}_{\mathrm{T}} / \mathrm{n}$ and $\delta \mathrm{D}_{\mathrm{T}}$ is therange of actual manufacturing deviations the component-fabrication process produces. 


\begin{tabular}{|c|c|c|c|}
\hline $\begin{array}{c}\text { Cylindrical } \\
\text { Assembly }\end{array}$ & $\begin{array}{c}\text { Mean } \\
\text { Diameter }\end{array}$ & $\begin{array}{c}\text { Mean } \\
\text { Gap }\end{array}$ & $\begin{array}{c}\text { Gap } \\
\text { Tolerance }\end{array}$ \\
\hline $\begin{array}{c}\text { Size-Selected } \\
\text { Pistons }\end{array}$ & $92 \mathrm{~mm}$ & $40 \mu \mathrm{m}$ & $\pm 18 \mu \mathrm{m}$ \\
\hline $\begin{array}{c}\text { Single-Size } \\
\text { Pistons }\end{array}$ & $96.5 \mathrm{~mm}$ & $30 \mu \mathrm{m}$ & $\pm 20 \mu \mathrm{m}$ \\
\hline $\begin{array}{c}\text { Std-LT3 Fit for } \\
\text {-100-mm Parts }\end{array}$ & $96 \mathrm{~mm}$ & $29 \mu \mathrm{m}$ & $\pm 4 \mu \mathrm{m}$ \\
\hline $\begin{array}{c}\text { Std-LT3 Fit for } \\
\text {-10-mm Parts }\end{array}$ & $10 \mathrm{~mm}$ & $14 \mu \mathrm{m}$ & $\pm 1.25 \mu \mathrm{m}$ \\
\hline $\begin{array}{c}\text { Earlier Valve } \\
\text { Lash Adjuster }\end{array}$ & $10 \mathrm{~mm}$ & $7.5 \mu \mathrm{m}$ & $\pm 2.5 \mu \mathrm{m}$ \\
\hline $\begin{array}{c}\text { Diesel } \\
\text { Fuel Injector }\end{array}$ & $10 \mathrm{~mm}$ & $2.5 \mu \mathrm{m}$ & $\pm 0.5 \mu \mathrm{m}$ \\
\hline $\begin{array}{c}\text { Newer Valve } \\
\text { Lash Adjuster }\end{array}$ & $10 \mathrm{~mm}$ & $\sim 1.0 \mu \mathrm{m}$ & $\ldots$ \\
\hline $\begin{array}{c}\text { Gasoline } \\
\text { Fuel Injector }\end{array}$ & $5 \mathrm{~mm}$ & $0.75 \mu \mathrm{m}$ & $\pm 0.25 \mu \mathrm{m}$ \\
\hline
\end{tabular}

Table 6. Mean diameter, mean gap, and gap tolerance for some actual and standard cylindrical-fit assemblies

\section{4c. Example Gap Values and Tolerances}

Table 6 shows the mean diameter, mean clearance-fit gap, and tolerance on that gap for a variety of micrometertolerance assemblies of piston-bore type in the modern automobile engine. These include the $40 \mu \mathrm{m}$ gap on 100 mm diameter engine piston-bore assemblies, a $7.5 \mu \mathrm{m}$ gap on an earlier-generation $10 \mathrm{~mm}$ diameter valve lashadjuster assembly, and a $0.75 \mu \mathrm{m}$ gap on a $5 \mathrm{~mm}$ gasoline fuel injector assembly.

Table 6 includes values of gap and gap tolerance for "standard LT3 cylindrical fits", the smallest-gap fits in the current standard on limits and fits of cylindrical assemblies [9]. For $100 \mathrm{~mm}$ diameter components, the classLT3 gap and gap tolerance are $29 \mu \mathrm{m} \pm 4 \mu \mathrm{m}$. For $10 \mathrm{~mm}$ diameter components, the LT3 gap and tolerance is $14 \mu \mathrm{m} \pm 1.25 \mu \mathrm{m}$.

LT3 designates the tightest "transition locational fit", intended for applications where, for example, accuracy of angular alignment or positional location is so important that both clearance and interference fits are within the 
tolerance limits on the value of the gap. For example, in the standard the tabulated values for maximum and minimum clerances for the LT3-class fit on $10 \mathrm{~mm}$ parts are, respectively, $+15.2 \mu \mathrm{m}$ and $-12.7 \mu \mathrm{m}$. The means and maximum deviation from them are the gaps and gap tolerances indicated above. As indicated by Table 4, there are a number of micrometer-tolerance cylindrical-fit assemblies in today's mass-produced automobile engines with assembly tolerances are already or just becoming smaller than any gap specified in the current standard on assembly limits and fits. Note that the value of the gap on the clearance fit of the single-size-class piston and cylinder shown virtually the same as the tighest transition fit in the current standard.

\section{Issues in DS\&T of Micrometer-Tolerance Assemblies}

The third principal part of the paper briefly discusses generic technology, measurements, and standards issues in the DS\&T of micrometer-tolerance assemblies at the variou sstages of the product cycle: design, component fabrication and measurement, assembly and test, and customer use.

\section{5a. Issues of DS\&T at the DesignStage}

A number of issues at the design stage of the product cycle reflect the impact of computerization. This occurs not only in operations at each stage of the product cycle but as the impact of the computerization at each stage is reflected back into the design stage proper. With design being created with $3 \mathrm{D}$ CAD representations of solidmodel features, with fabrication being done with $\mathrm{CNC}$ machines, with inspection being done with point-sample coordinate measuring systems, and with assembly being carried out with automation and robotics, computers generate, interpret, and implement designs. There are four problems areas associated with the computerization of the DS\&T of the automotive-assemblies which have been discussed above.

Design Data Transfer A long-standing and obvious issue is the lack of interoperability of CAD systems. It is not unusual for component suppliers having multiple customers each using different CAD systems to need multiple CAD systems themselves for design data exchange with their customers. However, one Californiabased component supplier reports needing to use eleven different CAD systems to deal with nine different customers. Given not only the increase in the number of supplier-customer exchanges of DS\&T data and the growing use in DS\&T of separate software packages for CAD, solid modeling, finite element analysis, tolerance stacking, assembly simulation systems and the like, the issue of non-interoperability of systems for DS\&T is an especially frustrating problem for both software users and vendors.

New GD\&T Standard In addition to interoperability, there are major computerization issues are associated with the technology of representation and interpretation of design intent. One such issue is that, because of computerization, design intent must now be represented with the freedom from ambiguity which only mathematical statements provide. Two new tolerancing standards address this requirement. One is on geometrical dimensioning and tolerancing, and the other is on its mathematicization $[10,11]$. Not yet fully addressed by such stan dards is the specification of cylindricity.

GD\&T of Cylinders Of the three main types of assembly tolerances - length, multple-fastener, and cylindrical, the most pervasive and problemmatic is the cylindrical. Cylindrical-fit assemblies include all the various of forms of shafts in bores, pistons in cylinders, and pins in holes. For example, micrometer-tolerance cylindrical-fit assemblies include the automotive piston-cylinder, fuel-injector, and valve-lifter systems discussed, as well as bearings in races and electronic printed-circuit-board connectors. The issue is the need for an effective, standardized, mathematically unambiguous way to dimension and tolerance cylinders, which have three- 
dimensional features now typically controlled by combination of tolerances on the two-dimensional features of size, circularity, straightness, and taper.

Point-Sample Systems Another computerization-related issue in DS\&T of geometrical features, such as cylindricity, is specification of the means of assessing conformity of geometrical features of fabricated components to specified tolerances when point-sample coordinate measurement systems, such as a coordinate measuring machine (CMM), are used. The specific and open issue is the need to be able to quantitatively determine the measurement uncertainty of CMM measurements. In the CMM measurement, that uncertainty depends upon the interaction of the following: the form of the manufacturing deviations; the location and number of points probed by the CMM; the measurement uncertainty at each point probed; the geometry of the substitute feature chosen to be fitted to the probed points; the algorithm employed to fit the points to the substitute feature; and the specific software implementation of that algorithm .

\section{5b. Issues in DS\&T at the Component-Fabrication Stage}

Among the issues in DS\&T of micrometer-tolerance assemblies at the component stage is the most basic one of achieving micrometer tolerances on components in high-volume production.

Speed of Precision Grinding In the fabrication of fuel-injection plungers and bores, where fuel metering is controlled by micrometer-tolerance fits, a current practice is to use through-feed grinding on the plunger with boring and honing to size on the bores. This process that does not meet the combination of daily volume of production and size-tolerance demands of the manufacturer.

Understanding of Ceramic Grinding Process One of the new materials for engine components being pursued by designers because of dimensional stability in extended use at high temperatures is ceramics. In the fabrication of various engine components such as valve stems, limitations on understanding of the ceramic grinding process prevent the material's and process's effective use in volume production.

Reproduceability of Injection Molding In the fabrication of a variety of polymer-component assemblies where electrical connections between mating elements of assemblies require micrometer-tolerance gaps, limits on dimensional reproducibility of plastic injection molding of components currently limits manufacturers ability to produce high volumes of defect-free products of that type.

\section{5c. Issues in DS\&T at the Component-Measurement Stage}

Among the issues in DS\&T of micrometer-tolerance assemblies at the component stage is the need for higheraccuracy higher-speed measurements of three-dimensional form in order to assure conformance to specification.

Accuracy on Long Cylinders Precision large-dimension cylinders pose a major challenge to even the most metrologically capable manufacturing companies. For example, tolerances of $1 \mu \mathrm{m}$ on roundness, $2 \mu \mathrm{m}$ on straightness, and $3 \mu \mathrm{m}$ on taper over the $300 \mathrm{~mm}$ length of a $35-\mathrm{mm}$ diameter hydraulic cylinder are reported by the one such company as being within its capability to precision machine, but beyond its ability to confidently measure.

High-Speed Gaging of Small Cylinders Because of its speed and precision, air-gaging is for size measurement of components to be assembled by size-selective assembly. Such assemblies include automobile engine valve stems, valve lifters, lash adjusters, and fuel injectors. Representative of very demanding gaging needs of this type 
is a U.S. manufacturer of fuel injectors who would like to be able to accurately measure (nominally $10 \mathrm{~mm}$ diameter) injector plungers with $0.5 \mu \mathrm{m}$ size-class tolerances a rate of 5000 per day. To the industry norms on measurement accuracies, typically 4-10 times less than tolerances, the implied accuracy would be of the order of $0.05-0.1 \mu \mathrm{m}$ delivered at the production rate indicated. According to one equipment supplier, limitations of air gaging may be a show-stopper in that area of application.

Distinguishing Size and Roughness For an increasing number of types of components with tight size tolerances, including those on components of fuel-injector and piston-cylinder assemblies, there is a problem in the dependence of the results of size measurements upon surface finish. For example, on engine pistons and fuel injectors, when size tolerances and the peak-to-peak surface finish are comparable, troublesome differences in results of measurement of size by means of air gaging and mechanical contact are encountered.

Optical Probing of Complex Geomteries For complex-geometry micrometer-tolerance components, such as jet-engine turbine blades and automobile transmission gears, where air gaging is not applicable and mechanical point-probing is too slow, manufacturers with higher-accuracy, higher-speeds requirements are pursuing development of hybrid optical-mechanical probe techniques to provide massively-parallel yet accurate pointsample measurement of complex forms.

\section{5d. Issues in DS\&T at the Assembly and Test Stage}

A major issue of DS\&T at the assembly stage of production of micrometer-tolerance assemblies which bears on design, specification, and tolerancing is the current inability to automate the assembly of various micrometertolerance components to the degree sought for large-volume production. Hydraulic, combustion, fuel-injection systems illustrate one such class of the assembly-automation problem. Assembly of each of these systems involves the classic peg-in-hole insertion problem of robotics compounded by tight tolerances.

High-Precision Angular Alignment In the case of $300 \mathrm{~mm}$ hydraulic cylinders, the longer cylinder requires especially precise angular alignment over the correspondingly longer travel.

Special Part Handling For automobile pistons, depending on the tightness of tolerances, combining the need to compress the piston rings on the piston and to precisely align piston-ring subassemblies with the cylinder bores in the piston-cylinder assembly operation still makes manual, rather than automated, insertion the practice in a number of engine plants.

Fits with Sub-Micrometer Tolerances For fuel injectors, $0.5 \mu \mathrm{m}$ size-class tolerances call for very great lateral as well as angular control to achieve effective insertion of the plunger into the bore. For this reason, manual and only partially mechanized assembly of micrometer-tolerance assemblies such as these is more the practice than some manufacturers would want.

\section{5e. Issues in DS\&T at the Final Product Stage}

A new issue of DS\&T for the final product stage of the product cycle of micrometer-tolerance assemblies is the growing need to be able to demonstrate to customers who purchase components and assemblies, that the processes which assure quality as conformance to DS\&T are formally documented.

Supplier Certification Throughout the auto industry, the norm is now for individual automobile manufacturers to impose their own supplier-certification requirements on those who manufacture components for their 
assemblies. Similarly, a growing number of other OEM as assemblers of supplier-fabricated components require ISO-9000 certification for their suppliers. An early DS\&T issue in such certification is the requirement to document an unbroken chain of traceability to international and national physical standards of the physical measurements made to determine conformity to tolerances. A proposal which extends the concept of documented traceability from measurements to geometrical dimensioning and tolerancing.

\begin{tabular}{|c|}
\hline $\begin{array}{c}\text { Geometric Product Specification (GPS) } \\
\text { "Chain of Standards" }\end{array}$ \\
\hline Product Documentation Indication \\
\hline Definition of Tolerances \\
\hline Definitions of Actual Features \\
\hline Assessment of Deviations of Workpiece \\
\hline Measurement Equipment Requirements \\
\hline Calibration Requirements \\
\hline
\end{tabular}

Table 7. The six staged types of documentary standards which need to be referenced to fully specify dimensions and tolerances within the proposed GPS system.

Geometric Product Specification GPS is the collective name for a variety of specfications on an engineering drawing proposed to formally define the geometric features of the component and its tolerances in terms of six stages from assignment of geometrical dimensions and tolerances to the measurement result used to decide conformity of a workpiece to those tolerances [12].

Table 7 shows the six stages of the GPS. These are: 1) Product Documentation Indication - the code of symbols for specifying geometric features of workpieces; 2) Definition of Tolerances - the theoretical definition and values of ideal, design-intent features; 3) Definitions of Actual Features - the characteristics or parameters to define the non-ideal real-world geometry in relation to the theoretical tolerance; 4) Assessment of the Deviations of the Workpiece - the detailed rules for comparing measurement results with tolearnce limits to decide upon accepting or rejecting the workpiece; 5) Measurement Equipment Requirements - the performance characteristics of the specific measuring equipment, including hardware and software, used to measure actual features; and 6) Calibration Requirements - the physical calibration standards and calibration procedures to be used to verify the accuracy and functional requirements of the specific measurement equipment with traceability to the international standard, such as the meter. The issue is that in this view of DS\&T, documentary standards would need to be explicitly referenced on the drawing for each of the six stages to be in full compliance with some future GPS standard. 


\section{Summary of the Approaches to DS\&T Discussed}

Table 8 is a summary in matrix form of the various approaches taken by the manufacturers of the automobileengine micrometer-tolerance assemblies discussed above. Each of those assemblies (valve-lifter, fuel-injector, piston-rod and piston-cylinder) has dimensions toleranced at the $1 \mu \mathrm{m}$ level. Each involves cylindrical limits and fits. This is one of the most pervasive, important, and difficult forms of assembly to design, specify, tolerance, and manufacture.

As used in this paper and shown in row 1 of Table 8, the product cycle consist of the design (I1), component (I2), assembly (I3) and product-use (I4) stages. Similarly, as used in the paper and shown in column I, the design stage the of product cycle includes: (12) design as the task of choosing an assembly's function and form; (13) specification, the task of defining the assembly's dimensions; and (I3) tolerancing, the task of determining the limits of permissible variations in those specified dimensions.

\begin{tabular}{|c|c|c|c|c|c|c|c|}
\hline \multicolumn{2}{|r|}{ I } & \multicolumn{2}{|r|}{ II } & \multicolumn{2}{|r|}{ III } & \multicolumn{2}{|r|}{ IV } \\
\hline 1 & DESIGN & $<>$ & COMPONENT & $<>$ & ASSEMBLY & $<>$ & PRODUCT \\
\hline 2 & $\begin{array}{l}\text { Design } \\
\text { Choosing } \\
\text { Assembly's } \\
\text { Form/Function }\end{array}$ & . & $\begin{array}{c}\text { Mechanical } \\
\text { Guide, Moving } \\
\text { Element, Bearing- } \\
\text { Seal Surface }\end{array}$ & \% & $\begin{array}{c}\text { Expanding } \\
\text { Combustion } \\
\text { Chamber }\end{array}$ & & $\begin{array}{l}\text { Explosive } \\
\text { Pressure to } \\
\text { Linear Motion } \\
\text { Conversion }\end{array}$ \\
\hline 3 & $\begin{array}{l}\text { Specification } \\
\text { Assigning } \\
\text { Assembly } \\
\text { "Dimension" }\end{array}$ & $\begin{array}{l}Y 14.5 M \\
Y 14.5 .1 \\
\text { GPS }\end{array}$ & $\begin{array}{c}\text { Diameters } \\
\mathrm{D}_{\mathrm{S}} \\
\mathrm{D}_{\mathrm{H}}\end{array}$ & $\begin{array}{l}\text { Standard } \\
\text { Classes } \\
\text { of Fits }\end{array}$ & Gap G & $\begin{array}{l}\text { Tight Fit- } \\
\text { Loose Fit } \\
\text { Trade- } \\
\text { offs }\end{array}$ & $\begin{array}{l}\text { Performance, } \\
\text { Reliability, } \\
\text { Cost and } \\
\text { Availability }\end{array}$ \\
\hline 4 & $\begin{array}{l}\text { Tolerancing } \\
\text { Determining } \\
\text { Acceptable } \\
\text { Variation }\end{array}$ & $I T G s$ & $\begin{array}{c}\delta \mathrm{D} \\
(\delta \mathrm{F})\end{array}$ & $\begin{array}{c}\text { Number of } \\
\text { Size } \\
\text { Classes, } \\
\text { VSA }\end{array}$ & $\Delta \mathrm{G}$ & $Q L F$ & $\Delta \mathrm{Q}$ \\
\hline
\end{tabular}

Table 7. Schematic representation of the relationships in design, specification, and tolerancing over the product cycle of the cylindrical-fit micrometer-tolerance automobile-engine assemblies including valve-lifter, fuel-injector, piston-rod, and piston-cylinder assemblies.

Design: Choosing Function The first set of tasks in the overall process of the DS\&T of micrometer-tolerance assemblies are those of the design phase (row 2). The design phase proceeds from choice of product function and form (IV2) back through choice of assembly function and form (III2) to choice of component function and form (II2). For example, for the combustion-engine pistons and cylinders: the product design function (IV2) is the conversion of pressure into linear motion and vice versa. The assembly design functions (III2) include containment of expanding combustion gases, mechanical guidance of motion, and sliding seal between stationary and moving elements. The component design functions (II2) include, for example for the piston, rigid-body force transmission, and for the cylinder, bearing surfaces. In each of the four examples of micrometer tolerance assemblies in the automobile engine described (the valve adjuster, fuel injector, piston-rod-wristpin, and pistonring-cylinder), the design form chosen to support product, assembly, and component design function is 
cylindrical. The assembly is comprised of close-fitting coaxial cylindrical components, which for elliptical pistons means the piston-ring combination in a cylindrical-bore cylinder.

Specification: Assigning Dimensions The intermediate set of tasks in the overall process of the DS\&T of micrometer-tolerance assemblies is the specification phase (row 3). In this specification phase of the design stage (I3), the values of the dimensions of components (II3) are derived from those on the assembly (III3) which proceed from those on the product (IV4).

For cylinder-in-cylinder assemblies, the principal assembly dimension is the gap G. As discussed in Appendix A, for various types of cylindrical fits, this gap can have a numerical value which is either positive, negative, or zero. For example, for the piston skirt and cylinder wall, there is a positive-gap clearance fit. In contrast, for the piston rings and cylinder wall, there is a zero-gap transition fit. One link between the assembly-specification dimension of gap and the product-specification dimension of quality (IV3-III3) are procedures which weigh quality gains and losses for tighter and looser fits. For example, in the case of the engine piston and cylinder, there is the trade off between a smaller clearance gap which reduces piston slapping but increases skuffing of skirt against wall.

For cylindrical-in-cylinder assemblies, the principal component dimension (II3) is diameter, where the relative values of the diameters of mating components derives from the assembly dimension, the gap (III3). Because each of the four engine-system examples is a cylindrical-fit assembly, a link (III3-II3) for relating diameters as component dimensions and gaps as assembly dimensions is the documentary standard definition of limits and fits.

Tolerancing: Determining Acceptable Variation The final and bottom-line set of tasks in the DS\&T of micrometer-tolerance assemblies is the tolerancing phase (row 4). In the approach represented here, tolerances on components (II4) are derived from tolerances on the assembly (III4) which derive from tolerances on the product dimension (IV4). In today's automobile companies, the principal product dimension (IV3) is quality in the extended sense, which includes product performance, reliability, cost, and availability. For many automobile manufacturers, the tolerance or acceptable variation in that product dimension (IV4) is defined by the Taguchi concept of "quality loss", the sum of all costs to the customer due to poor product quality. A link (III4-IV4) between the tolerance on the product dimension, $\Delta Q$, and the tolerance on the assembly dimension, $\Delta G$, is the Taguchi quality loss function. In the Taguchi approach, design of experiment can be used to define an empirical relation between quality variation and gap variation.

For deriving component tolerances from assembly tolerances (II4-III4), there is a mathematical relation corresponding to each of the size-classification strategies of single- or multiple-size-class assembly. Variation simulation analysis, which involves Monte-Carlo calculations of assembly variations as a function of component variations,also provides a means for relating the assembly and component tolerances. Note that VSA can also deal with form tolerances $(\delta \mathrm{F})$ on cylindrical fits, which even worst-case analytical calculations cannot. Note also finally, that the new documentary standards on geometrical dimensioning and tolerancing, the proposed Global Product Specification system, and the currently standarized International Tolerance Grades provide some means for formally linking the design and component stages at the specification (I3-II3) and tolerancing (I4-II4) phases.

\section{Conclusion}

As this paper shows, many economically vital U.S. products are comprised of assemblies with components toleranced at the micrometer level. Such tolerances place assemblies at or beyond the limits of what is attainable 
with fully interchangeable parts. As a result, the design, specification, and tolerancing of such assemblies requires special care. A major aspect of this care is accounting for potential issues and problems associated which arise at each stage of the product cycle. Major advances in technology, especially computerization, have been sources of both new capabilities and new problems at virtually every stage of the cycle. Although proprietary concerns are a dominant consideration in how such problems are attacked, many of the problems have generic technology, measurements and standards aspects which institutions working on such matters can help address.

\section{Appendix A. Relations Among Dimensions and Tolerances of Standard Classes of Cylindrical Fits}

The gap between two elements of a clindrical-fit assembly, generally called the shaft and the hole, has a range of values determined by the maximum amd minimum values of hole and shaft diameters. Classes of fits are defined in standards on limits and fits of cylindrical assemblies in terms of tabulated signed values of maximum and minimum amounts of interference $(-)$ and clearance $(+)$ resulting from application of standard tolerance limits. In this paper, these tabulated values are converted to gaps by simple algebraic combination. These gaps and gap tolerances are also related simply to shaft and hole diameters and tolerances. Given a hole diameter $\mathrm{D}_{\mathrm{H}}$, a shaft diameter $D_{S}$, and a tolerance on each of $\delta \mathrm{D}$, the maximum, mean and minimum clearances (gaps) are given respectively by the relations:

$$
\begin{aligned}
\mathrm{G}(\max ) & =D_{H}(\max )-D_{S}(\min ) \\
& =\left(D_{H}+\delta D\right)-\left(D_{S}-\delta D\right) \\
& =\left(D_{H}-D_{S}\right)+2 \delta D, \\
G(\min ) & =D_{H}(\min )-D_{S}(\max ) \\
& =\left(D_{H}-\delta D\right)-\left(D_{S}+\delta D\right) \\
& =\left(D_{H}-D_{S}\right)-2 \delta D \\
G(\text { mean }) & =1 / 2\{G(\max )+G(\min )\} \\
& =1 / 2\left(D_{H}+D_{S}\right) . \\
\Delta G & =1 / 2\{G(\max )-G(\min )\} \\
& = \pm 2 \delta D .
\end{aligned}
$$

\begin{tabular}{|c|c|c|c|c|c|}
\hline $\begin{array}{c}\text { General } \\
\text { Type }\end{array}$ & $\begin{array}{c}\text { Specific } \\
\text { Sub-Type }\end{array}$ & Class & $\begin{array}{c}\text { Max } \\
\text { Gap }\end{array}$ & $\begin{array}{c}\text { Mean } \\
\text { Gap }\end{array}$ & $\begin{array}{c}\text { Min } \\
\text { Gap }\end{array}$ \\
\hline Clearance & & $\mathrm{C}$ & + & + & + \\
\hline \multirow{4}{*}{ Locational } & Clearance & LC & + & + & -0 \\
\cline { 2 - 6 } & Transition & LT3 & + & -0 & - \\
\cline { 2 - 6 } & Interference & LN & -0 & - & - \\
\hline Interference & & $\mathrm{N}$ & - & - & - \\
\hline
\end{tabular}

Table A1. Algebraic values of the maximum, mean, and minimum clearances between shafts and bores for the major and specific standard classes of cylindrical fits 
The algebraic values of the maximum, mean and minimun clearances (gaps) for the three general types of cylindrical fits and three types of locational fits are shown in Table Al. Clearance fits are designated class C and for them the maximum, minimum and mean values of the gap are all positive. Interference fits are designated class $\mathrm{N}$ and for them the maximum, minimum, and mean values of the gap are all negative. Locational fits are designated $\mathrm{L}$ and may be of clearance, interference, or transition types. For locational -class fits, either the maximum or the minimum or the mean value of the gap is zero. The critical locational-transition class, LT3, is the zero-crossing fit, with a maximum gap of positive value (clearance-fit), a mean gap of zero value (transition-fit), and a minumum gap of negative value (interference-fit).

\section{References}

1. American National Standard ANSI B4.1-1967 (R1979) "Preferred Limits and Fits for Cylindrical Parts", American Society of Mechanical Engineers, New York NY, 1979.

2. American National Standard B4.2 -1972 (R1978) "Preferred Metric Limits and Fits for Cylindrical Parts”, American Society of Mechanical Engineers, New York NY, 1978.

3. Fortini, E.T., "Dimensions and Tolerances", in Mechanical Design and Systems Handbook, 2nd ed., E.T. Fortini, 1985.

4. Oberg, E., et al, "Machinery's Handbook”, 23rd ed., 1988.

5. Swyt, D.A., "Challenges to NIST in Dimensional Metrology: The Impact of Tightening Tolerances in the U.S. Discrete-Part Manufacturing Industry”, NISTIR 4757, National Institute of Standards and Technology, Gaithersburg, MD 20899, Jan 1992.

6. Taniguchi, N., Current Status and Future Trends of Ultra-Precision Machining and Ultrafine Materials", Annals of the CIRP, Vol. 2, No. 2, 1983.

7. Early, R. And J.Thompson, "Variation Analysis (at GM) Using Monte Carlo Techniques", Proceedings of ASME Conference on Failure Prevention and Analysis, Design Engineering Vol. 16, pp. 139-144, 1989.

8. Chrysler Quality Council Award for Dash Panel Design Based on Variation Simulation Analysis, Chrysler Corporation Times, Vol. 12, No. 23, June 18, 1992.

9. ANSI National Standard Transition Locational Fits (ANSI B4.1-1967, R1979)] Table 4 in Oberg, E., et al, "Machinery's Handbook", 23rd ed., p.640, 1988.

10. American National Standard ASME Y14.5M-1994 [Revision of ANSI Y14.5M-1982 (R1988)], American Society of Mechanical Engineers, New York NY, 1994.

11. American National Standard ANSU/ASME Y14.5.1-1994, Mathematical Definition of Dimension and Tolerancing Principles, American Society of Mechanical Engineers, New York NY, Jan. 1995.

12. Bennich, P., “Chain of Standards: A New Concept in GPS Standards”, Manufacturing Review, Vol. 7, No. 1, pp. 29-38, Mar 1994. 



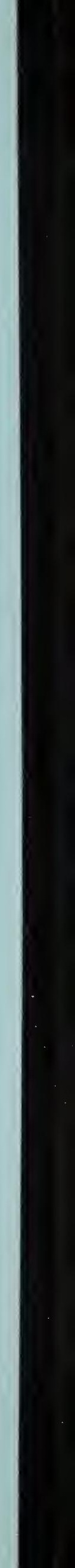

